\title{
Kasuistik
}

\section{Oboenspieler mit Blähhals}

\author{
Bei einer Matinee im Münchner Gärtnerplatztheater wurde Harmoniemusik* von Mozart \\ durch ein Bläsernonett gegeben. Kaum hatte die Gruppe zu spielen begonnen, konnten die \\ meisten Zuhörer ihre Augen nicht mehr vom Hals eines der beiden Oboisten lassen. Wenn er \\ zu blasen anfing, blähten sich beide Halsseiten gewaltig auf - fast wie bei einem Frosch.
}

_ Der 40-jährige professionelle Oboist fühlte sich gesund und war beschwerdefrei, insbesondere hatte er keine Probleme beim Schlucken oder Atmen. Nachdem er aber schon öfter auf den Blähhals angesprochen worden war und ihn das Phänomen selbst beunruhigte, ließ er sich in der HNO-Ambulanz der örtlichen Universitätsklinik untersuchen.

Der Halsumfang betrug im nativen Zustand 38,5 cm (Abb. 1), beim Blasen $48 \mathrm{~cm}$ (Abb. 2). Bei der laryngoskopischen Untersuchung ergab sich ein anatomisch und funktionell unauffälliger Larynx. Bei Erhöhung des supraglotti-

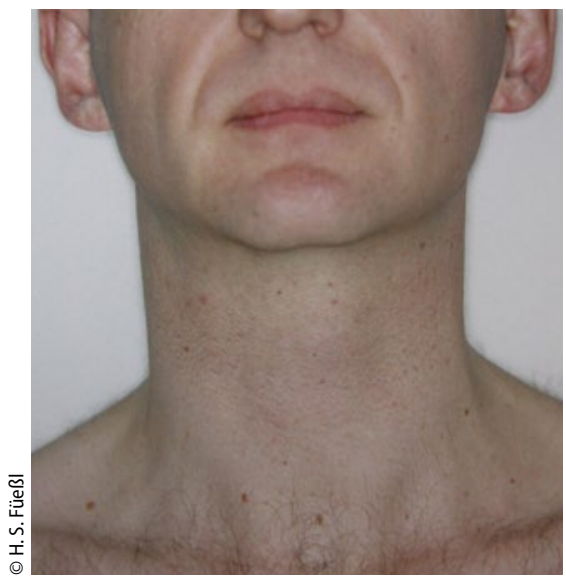

Abb. 1 Nativzustand des Halses. schen Drucks stellte sich eine massive zirkuläre Ausweitung des Hypopharynx mit beidseitiger, äußerlich sichtbarer, infrahyoidaler Vorwölbung dar. Nach Druckentlastung bildete sich der Befund rasch und vollständig zurück.

\section{Diagnose: Megapharynx}

Es handelt sich um einen Megapharynx mit beidseitiger Pharyngozelenbildung. Durch die anhaltende Druckerhöhung bei Blasmusikern kommt es bei wahrscheinlich angeborener muskulärer Wandschwäche des Pharynx zu dessen Erweiterung und eventuell zur Ausbil-

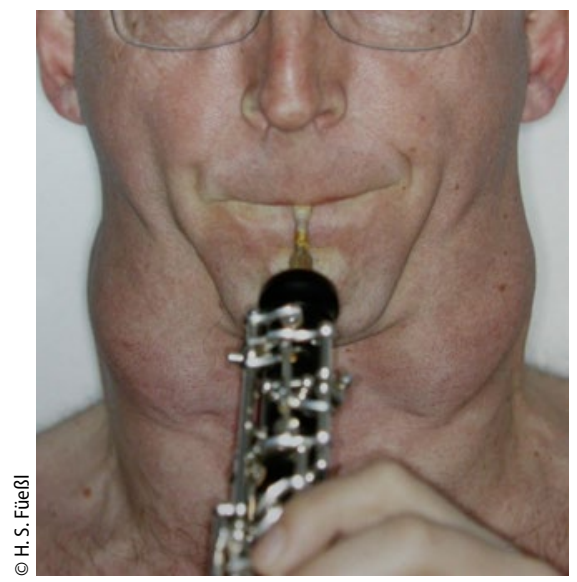

Abb. 2 Hals beim Blasen der Oboe. dung von kleinen Divertikeln in Höhe der Membrana thyreoidea. Die klinische Verdachtsdiagnose konnte in einer funktionellen CT bestätigt werden.

\section{Halskrause wurde nicht akzeptiert}

Man riet dem Mann vorerst von einem operativen Eingriff ab, da bei ihm als professionellem Blasmusiker eine fortwährende Druckbelastung bestand und ein Rezidiv sehr wahrscheinlich war. Stattdessen wurde ihm empfohlen, während des Spiels eine nach Maß angefertigte elastische Halskrause zu tragen. Bei einer täglichen Spielzeit von mehreren Stunden - beim Üben, bei Auftritten wie auch beim Musikunterricht geben konnte sich der Mann mit dieser Maßnahme aber nicht anfreunden.

\section{$\rightarrow$ Anschrift des Verfassers:}

Prof. Dr. med. Hermann S. Füeß। Internist und Gastroenterologe Privatpraxis für Integrative Innere Medizin Renatastr. 30, D-80639 München E-Mail:hsfuessl@t-online.de

* In der sog. Harmoniemusik wurden die gängigsten Arien von Opern rasch nach der Erstaufführung für ein Bläserensemble umgeschrieben, um diese "Top Hits" in der Zeit vor dem Aufkommen von Tonträgern auch ohne großes Orchester unter die Leute zu bringen. Für Mozart und andere Komponisten seiner Zeit waren diese Partituren eine wichtige Einnahmequelle. 